\title{
Lymph node retrieval in colorectal cancer: determining factors and prognostic significance
}

\author{
Johannes Betge ${ }^{1} \cdot$ Lars Harbaum $^{2} \cdot$ Marion J. Pollheimer $^{3} \cdot$ Richard A. Lindtner $^{4}$. \\ Peter Kornprat $^{5} \cdot$ Matthias P. Ebert $^{1} \cdot$ Cord Langner $^{3}$
}

Accepted: 3 February 2017 / Published online: 16 February 2017

(C) The Author(s) 2017. This article is published with open access at Springerlink.com

\begin{abstract}
Purpose The study aimed to analyze clinicopathological factors that determine the extent of lymph node retrieval and to evaluate its prognostic impact in patients with colorectal cancer (CRC).

Methods The number of retrieved lymph nodes was analyzed in 381 CRC specimens. Lymph node count was related to different clinicopathological variables by binary logistic regression. Progression-free survival (PFS) and cancer-specific survival (CSS) were determined using the Kaplan-Meier method and Cox regression models.

Results The median number of retrieved lymph nodes was 20 (mean $21 \pm 10$, range 1-65) in right-sided, $13(16 \pm 10,1-66)$ in left-sided, and $15(18 \pm 11,3-64)$ in rectal tumors. The number of retrieved lymph nodes was independently associated with T-classification $(p<0.001), \mathrm{N}$-classification $(p=0.014)$, and tumor size $(p=0.005)$ as well as rightsided tumor location $(p=0.012)$. There was no association with age, sex, tumor grade, mismatch-repair status, and lymph or blood vessel invasion. The longer the surgical specimen, the higher were the numbers of retrieved and positive lymph
\end{abstract}

Cord Langner

cord.langner@medunigraz.at

1 Department of Medicine II, University Hospital Mannheim, Medical Faculty Mannheim, Heidelberg University, Mannheim, Germany

2 Department of Medicine II, University Medical Center Hamburg-Eppendorf, Hamburg, Germany

3 Institute of Pathology, Medical University of Graz, Auenbruggerplatz 25, 8036 Graz, Austria

4 Department of Surgery, Medical University of Innsbruck, Innsbruck, Austria

5 Department of Surgery, Division of General Surgery, Medical University of Graz, Graz, Austria nodes $(p<0.001$, respectively). In patients with locally advanced (T3/T4) tumors $(n=283)$, analysis of more than 12 lymph nodes was independently associated with PFS $(\mathrm{HR}=0.63, p=0.025)$ and CSS $(\mathrm{HR}=0.54, p=0.004)$. In the subset of T3/T4 N0 patients $(n=130)$, analysis of more than 12 lymph nodes similarly proved to be an independent predictor of outcome (PFS, HR $=0.48, p=0.046$; OS, $\mathrm{HR}=0.41, p=0.026$ ).

Conclusion The number of retrieved lymph nodes is associated with higher tumor stage, tumor size, and right-sided location. Low lymph node count indicates adverse outcome in patients with locally advanced (T3/T4) disease.

Keywords Lymph node · Prognostic factor · Colon cancer . Rectum cancer $\cdot$ Multivariate analysis

\section{Introduction}

Colorectal cancer (CRC) is globally the third most commonly diagnosed cancer in males and the second most common in females [1]. It is thus a major contributor to cancer morbidity and mortality worldwide.

In CRC, the involvement of lymph nodes by tumor cells represents a major step to systemic tumor spread and is therefore a strong indicator of adverse prognosis [2]. Lymph node involvement is a determining variable of the AJCC/UICC TNM system, which is currently the most relevant prognostic classification and used as basis for therapeutic decisions [3, 4]. Specifically, patients without evidence of distant metastasis undergoing resection for primary colon cancer may receive adjuvant chemotherapy mainly based upon the identification of metastatic lymph nodes [5].

Adequate lymphadenectomy and sufficient lymph node retrieval from the resected specimen are crucial to ensure 
accuracy in staging, especially to prevent under-diagnosis of lymph node involvement by tumor cells [6, 7]. Additionally, a higher number of sampled lymph nodes has emerged as independent prognostic factor for improved survival in several previous studies, especially in stage II CRC [6-11]. Hence, adjuvant chemotherapy has been recommended by current practice guidelines in case of inadequately sampled numbers of lymph nodes, even if no involvement of lymph nodes by tumor cells is found [12]. However, data are conflicting, and not all studies showed improved outcome for CRC patients when more lymph nodes had been retrieved [13-15]. The number of retrieved lymph nodes may depend on different factors, including surgical radicality and dedicated pathological work-up, but also on patient- and tumor-specific factors [6,7].

International guidelines currently recommend sampling of a minimum number of 12 lymph nodes. Evidence, however, is weak, and it is not known, whether the sampling of more than 12 nodes improves staging accuracy and prognosis [6, 7]. It is therefore an ongoing debate how many lymph nodes need to be sampled for optimal staging. It is likewise unclear whether the cut-off value of 12 nodes should be adjusted by patient- or tumor-specific factors.

Therefore, our study aimed to analyze different clinicopathological factors that determine the extent of lymph node retrieval and to evaluate the prognostic impact of the extent of lymph node retrieval in a large cohort of CRC patients.

\section{Patients and methods}

\section{Patient cohort}

Our cohort consisted of 381 patients including 166 (44\%) females and 215 (56\%) males (ratio 1:1.3). Mean age was 68.5 years (median 70.1, range 28-93). Case selection of our cohort has been described in detail previously [16]. Briefly, 400 CRC patients treated from January 1992 through December 2000 at one institution (Medical University of Graz, Austria) were randomly selected from the CRC database of the Institute of Pathology, Medical University of Graz. We excluded patients with $\mathrm{T} 1$ cancer treated by endoscopic polypectomy, patients that received neoadjuvant chemotherapy or radiotherapy, and patients with syn- or metachronous invasive cancers originating from the colorectum or other sites. In total, 381 resection specimens from 400 patients $(95 \%)$ were available for review pathology. AJCC/UICC stage determined treatment of our patients. Stage III patients received adjuvant chemotherapy with 5-fluorouracil/folinic acid according to the Mayo Clinic regimen [17]. Stage I and II patients did not receive adjuvant therapy. Patients with stage IV disease were treated with different combination chemotherapy regimens according to the choice of the treating physician. Follow-up of our cohort has been described in a previous publication [16]. It included at least chest X-rays and abdominal ultrasound every 6 months for the first 3 years and yearly thereafter. Disease progression was defined as local tumor recurrence or development of distant metastasis.

The investigation was carried out in accordance with the Declaration of Helsinki. The study was approved by the Institutional Review Board of the Medical University of Graz, Austria. For this retrospective study, formal consent of each patient is not required.

\section{Pathological evaluation}

Original histopathological slides were independently reevaluated by two gastrointestinal pathologists (M.J.P. and C.L.). Tumor stage was assessed according to the 7th edition of the AJCC/UICC TNM classification [4]. Histological tumor type and tumor grade were analyzed according to the WHO guidelines [18]. Tumors located in the rectum or at the rectosigmoid junction were summarized as rectal cancers. Tumors originating from sigmoid colon to the left colonic flexure were defined as left-sided cancers, while tumors located from transverse colon to caecum were defined as rightsided cancers. The presence of lymph and/or blood vessel invasion was assessed as carcinoma being present in vessels with an unequivocal endothelial lining (lymphatic invasion) or in vessels with a thick vascular wall and red blood cells in the lumen (blood vessel invasion) [16]. Mismatch-repair (MMR) status was assessed by immunohistochemistry as described earlier, using antibodies directed against MLH1, MSH2, and MSH6 [19]. The loss of immunoreactivity for at least one of the three markers characterized MMR-deficient tumors [20]. No special fat clearance or staining techniques were used for lymph node harvesting.

\section{Statistical analysis}

Associations with AJCC/UICC stage, T-classification, N-classification, grade, MMR status, location, tumor size, lymphatic invasion, and venous invasion were analyzed using the Chi square test or Student's $t$ test. Coefficients of correlation were determined by Pearson's $r$. Binary logistic regression model including an intercept was applied to assess the influence of primary tumor characteristics on the number of retrieved lymph nodes. The Hosmer-Lemeshow-test was used to assess goodness of fit of the model. Cause of death was determined by treating physicians and/or by chart review and was corroborated by death certificates if available. Progression-free survival (PFS) and cancer-specific survival (CSS) were investigated using the Kaplan-Meier method and compared by the log-rank test. For multivariable testing, Cox proportional hazards regression models were performed. Statistical calculations were performed using SPSS version 20.0 (IBM, 
Armonk, NY, USA). All reported $p$ values were two-sided with significance at $p<0.05$.

\section{Results}

A mean number of $18.1 \pm 10.7$ lymph nodes (median 16, range $1-66)$ were retrieved in our patients. Specifically, the number was $21 \pm 10.5$ (median 20, range 1-65) in right-sided, $15.6 \pm 9.8$ $(13,1-66)$ in left-sided, and $17.9 \pm 11(15,3-64)$ in rectal tumors (Fig. 1a). Twelve or more lymph nodes were sampled in $270(70.9 \%)$ cases. Positive lymph nodes were detected in $168(44 \%)$ patients. The number of retrieved lymph nodes was higher in patients with lymph node positive tumors compared with patients with lymph node negative tumors (mean $20 \pm 11.8$ versus $16.6 \pm 9.5 ; p=0.002$, Fig. 1b). This difference was particularly pronounced in patients with rectal cancer (N0 $15.4 \pm 9.3$ retrieved lymph nodes versus N1/2 $20.9 \pm 12.3$, $p=0.001)$ and almost significant in left-sided colon cancers (N0 $14.1 \pm 8.9$ versus N1/2 $17.5 \pm 10.6, p=0.075$ ), while no difference was observed in right-sided cancers (N0 $20.7 \pm 9.1$ versus N1/2 $21.5 \pm 12.1, p=0.707$, Fig. $1 \mathrm{c}-\mathrm{e}$ ).

We categorized the number of retrieved lymph nodes into four groups (1-9, 10-19, 20-29, and >29). With this classification, a higher number of sampled nodes was significantly associated with higher T-classification $(p<0.001)$, higher AJCC/UICC stage $(p<0.001)$, larger tumor size $(p=0.030)$, and right-sided tumor location $(p<0.001)$. Association with $\mathrm{N}$-classification was nearly significant $(p=0.059)$. There was no association with age, sex, grade, mismatch-repair status, and lymph or blood vessel invasion (Table 1).

In a binary logistic regression model, tumor size, T-classification, N-classification, and right tumor localization proved to be to independently associated with the retrieval of more than the recommended 12 lymph nodes (Table 2).

Of note, the length of the surgical resection CRC specimen (data available for 359 patients) correlated positively with the number of retrieved lymph nodes $(r=0.436 ; p<0.001)$ and with the number of lymph nodes involved by tumor cells $(r=0.18 ; p=0.001)$. That is, the longer the CRC specimen,
Fig. 1 Numbers of retrieved lymph nodes in right-sided colon cancers, left-sided colon cancers, and rectum cancers (a). Numbers of retrieved lymph nodes in patients with node negative and node positive tumors analyzing all cases (b). Restricted to rightsided tumors (c). Restricted to left-sided tumors (d). Restricted to rectum cancers (e)

\section{a}

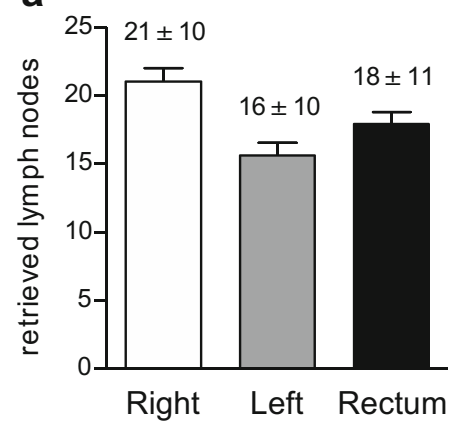

$$
\text { C }
$$

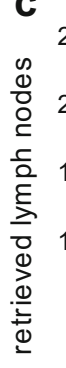$$
\text { Right Left Rectum }
$$
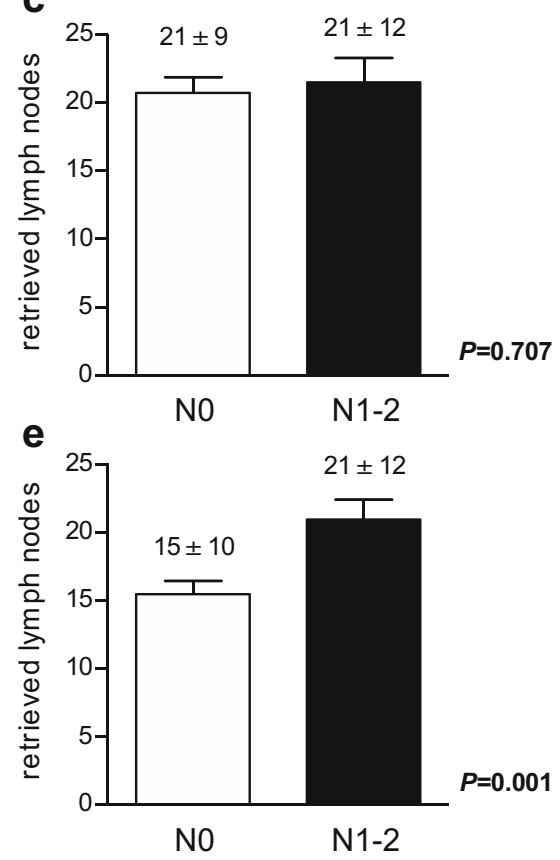

b
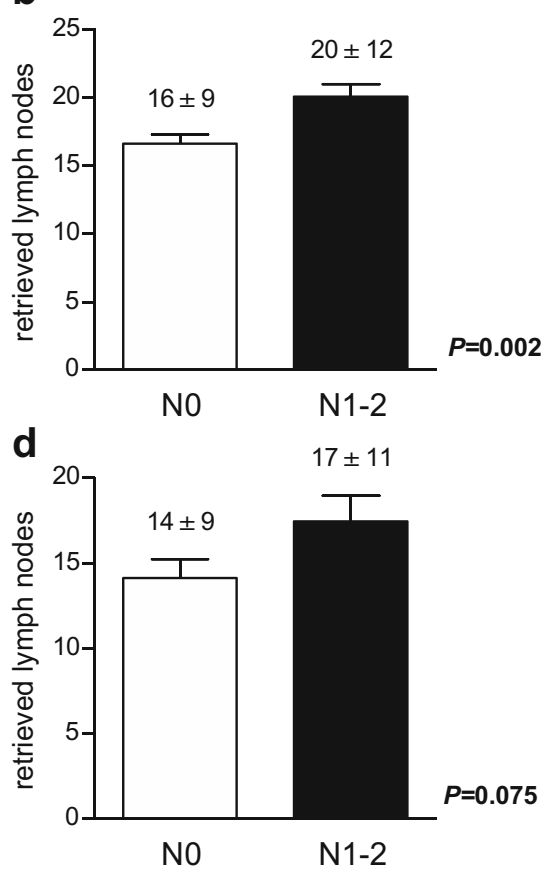
Table 1 Associations of the number of retrieved lymph nodes with different clinicopathological parameters

\begin{tabular}{|c|c|c|c|c|c|c|c|c|c|c|}
\hline \multirow[b]{2}{*}{ Age } & \multirow[b]{2}{*}{$\begin{array}{l}\leq 70 \\
>70\end{array}$} & \multicolumn{2}{|c|}{ 1-9 Lymph nodes } & \multicolumn{2}{|c|}{ 10-19 Lymph nodes } & \multicolumn{2}{|c|}{ 20-29 Lymph nodes } & \multicolumn{2}{|c|}{ >29 Lymph nodes } & \multirow{2}{*}{$\frac{p \text { value }}{0.95}$} \\
\hline & & $\begin{array}{l}40 \\
39\end{array}$ & $\begin{array}{l}(21.1 \%) \\
(20.4 \%)\end{array}$ & $\begin{array}{l}77 \\
83\end{array}$ & $\begin{array}{l}(40.5 \%) \\
(43.5 \%)\end{array}$ & $\begin{array}{l}51 \\
48\end{array}$ & $\begin{array}{l}(26.8 \%) \\
(25.1 \%)\end{array}$ & $\begin{array}{l}22 \\
21\end{array}$ & $\begin{array}{l}(11.6 \%) \\
(11 \%)\end{array}$ & \\
\hline Sex & $\begin{array}{l}\text { Female } \\
\text { Male }\end{array}$ & $\begin{array}{l}40 \\
39\end{array}$ & $\begin{array}{l}(18.6 \%) \\
(23.5 \%)\end{array}$ & $\begin{array}{l}96 \\
64\end{array}$ & $\begin{array}{l}(44.7 \%) \\
(38.6 \%)\end{array}$ & $\begin{array}{l}56 \\
43\end{array}$ & $\begin{array}{l}(26 \%) \\
(25.9 \%)\end{array}$ & $\begin{array}{l}23 \\
20\end{array}$ & $\begin{array}{l}(10.7 \%) \\
(12 \%)\end{array}$ & 0.56 \\
\hline T-classification & $\begin{array}{l}1 \\
2 \\
3 \\
4\end{array}$ & $\begin{array}{r}12 \\
23 \\
37 \\
7\end{array}$ & $\begin{array}{l}(42.9 \%) \\
(32.9 \%) \\
(17 \%) \\
(10.8 \%)\end{array}$ & $\begin{array}{l}13 \\
39 \\
82 \\
26\end{array}$ & $\begin{array}{l}(46.4 \%) \\
(55.7 \%) \\
(37.6 \%) \\
(40 \%)\end{array}$ & $\begin{array}{r}2 \\
5 \\
74 \\
18\end{array}$ & $\begin{array}{l}(7.1 \%) \\
(7.1 \%) \\
(33.9 \%) \\
(27.7 \%)\end{array}$ & $\begin{array}{r}1 \\
3 \\
25 \\
14\end{array}$ & $\begin{array}{l}(3.6 \%) \\
(4.3 \%) \\
(11.5 \%) \\
(21.5 \%)\end{array}$ & $<0.001$ \\
\hline $\mathrm{N}$-classification & $\begin{array}{l}0 \\
1 \\
2\end{array}$ & $\begin{array}{r}51 \\
19 \\
9\end{array}$ & $\begin{array}{l}(23.9 \%) \\
(22.9 \%) \\
(10.6 \%)\end{array}$ & $\begin{array}{l}94 \\
28 \\
38\end{array}$ & $\begin{array}{l}(44.1 \%) \\
(33.7 \%) \\
(44.7 \%)\end{array}$ & $\begin{array}{l}49 \\
26 \\
24\end{array}$ & $\begin{array}{l}(23 \%) \\
(31.3 \%) \\
(28.2 \%)\end{array}$ & $\begin{array}{l}19 \\
10 \\
14\end{array}$ & $\begin{array}{l}(8.9 \%) \\
(12 \%) \\
(16.5 \%)\end{array}$ & 0.059 \\
\hline AJCC/UICC stage & $\begin{array}{l}\text { I } \\
\text { II } \\
\text { III } \\
\text { IV }\end{array}$ & $\begin{array}{l}27 \\
18 \\
20 \\
14\end{array}$ & $\begin{array}{l}(33.3 \%) \\
(15 \%) \\
(15.9 \%) \\
(25.9 \%)\end{array}$ & $\begin{array}{l}45 \\
47 \\
50 \\
18\end{array}$ & $\begin{array}{l}(55.6 \%) \\
(39.2 \%) \\
(39.7 \%) \\
(33.3 \%)\end{array}$ & $\begin{array}{r}6 \\
40 \\
38 \\
15\end{array}$ & $\begin{array}{l}(7.4 \%) \\
(33.3 \%) \\
(30.2 \%) \\
(27.8 \%)\end{array}$ & $\begin{array}{r}3 \\
15 \\
18 \\
7\end{array}$ & $\begin{array}{l}(3.7 \%) \\
(12.5 \%) \\
(14.3 \%) \\
(13 \%)\end{array}$ & $<0.001$ \\
\hline Tumor grade & $\begin{array}{l}1 \\
2 \\
3 \\
4\end{array}$ & $\begin{array}{r}35 \\
29 \\
10 \\
5\end{array}$ & $\begin{array}{l}(23.5 \%) \\
(20 \%) \\
(16.4 \%) \\
(19.2 \%)\end{array}$ & $\begin{array}{r}58 \\
66 \\
28 \\
8\end{array}$ & $\begin{array}{l}(38.9 \%) \\
(45.5 \%) \\
(45.9 \%) \\
(30.8 \%)\end{array}$ & $\begin{array}{r}43 \\
36 \\
11 \\
9\end{array}$ & $\begin{array}{l}(28.9 \%) \\
(24.8 \%) \\
(18 \%) \\
(34.6 \%)\end{array}$ & $\begin{array}{r}13 \\
14 \\
12 \\
4\end{array}$ & $\begin{array}{l}(8.7 \%) \\
(9.7 \%) \\
(19.7 \%) \\
(15.4 \%)\end{array}$ & 0.27 \\
\hline $\mathrm{L}$ & $\begin{array}{l}\text { L0 } \\
\text { L1 }\end{array}$ & $\begin{array}{l}50 \\
29\end{array}$ & $\begin{array}{l}(19.6 \%) \\
(23 \%)\end{array}$ & $\begin{array}{r}112 \\
48\end{array}$ & $\begin{array}{l}(43.9 \%) \\
(38.1 \%)\end{array}$ & $\begin{array}{l}69 \\
30\end{array}$ & $\begin{array}{l}(27.1 \%) \\
(23.8 \%)\end{array}$ & $\begin{array}{l}24 \\
19\end{array}$ & $\begin{array}{l}(9.4 \%) \\
(15.1 \%)\end{array}$ & 0.27 \\
\hline $\mathrm{V}$ & $\begin{array}{l}\text { V0 } \\
\text { V1 }\end{array}$ & $\begin{array}{l}62 \\
17\end{array}$ & $\begin{array}{l}(21.1 \%) \\
(19.5 \%)\end{array}$ & $\begin{array}{r}124 \\
36\end{array}$ & $\begin{array}{l}(42.2 \%) \\
(41.4 \%)\end{array}$ & $\begin{array}{l}77 \\
22\end{array}$ & $\begin{array}{l}(26.2 \%) \\
(25.3 \%)\end{array}$ & $\begin{array}{l}31 \\
12\end{array}$ & $\begin{array}{l}(10.5 \%) \\
(13.8 \%)\end{array}$ & 0.87 \\
\hline Tumor size & $\begin{array}{l}\leq 4.5 \\
>4.5\end{array}$ & $\begin{array}{l}28 \\
51\end{array}$ & $\begin{array}{l}(30.8 \%) \\
(17.6 \%)\end{array}$ & $\begin{array}{r}38 \\
122\end{array}$ & $\begin{array}{l}(41.8 \%) \\
(42.1 \%)\end{array}$ & $\begin{array}{l}18 \\
81\end{array}$ & $\begin{array}{l}(19.8 \%) \\
(27.9 \%)\end{array}$ & $\begin{array}{r}7 \\
36\end{array}$ & $\begin{array}{l}(7.7 \%) \\
(12.4 \%)\end{array}$ & 0.030 \\
\hline Tumor location & $\begin{array}{l}\text { Right } \\
\text { Left } \\
\text { Rectum }\end{array}$ & $\begin{array}{l}13 \\
35 \\
31\end{array}$ & $\begin{array}{l}(12.1 \%) \\
(31.8 \%) \\
(18.9 \%)\end{array}$ & $\begin{array}{l}34 \\
44 \\
82\end{array}$ & $\begin{array}{l}(31.8 \%) \\
(40 \%) \\
(50 \%)\end{array}$ & $\begin{array}{l}43 \\
23 \\
33\end{array}$ & $\begin{array}{l}(40.2 \%) \\
(20.9 \%) \\
(20.1 \%)\end{array}$ & $\begin{array}{r}17 \\
8 \\
18\end{array}$ & $\begin{array}{l}(15.9 \%) \\
(7.3 \%) \\
(11 \%)\end{array}$ & $<0.001$ \\
\hline MMR status & $\begin{array}{l}\text { Deficient } \\
\text { Proficient }\end{array}$ & $\begin{array}{r}5 \\
72\end{array}$ & $\begin{array}{l}(21.7 \%) \\
(20.6 \%)\end{array}$ & $\begin{array}{r}10 \\
147\end{array}$ & $\begin{array}{l}(43.5 \%) \\
(42 \%)\end{array}$ & $\begin{array}{r}6 \\
90\end{array}$ & $\begin{array}{l}(26.1 \%) \\
(25.7 \%)\end{array}$ & $\begin{array}{r}2 \\
41\end{array}$ & $\begin{array}{l}(8.7 \%) \\
(11.7 \%)\end{array}$ & 0.95 \\
\hline
\end{tabular}

the higher was the number of retrieved and also the number of positive lymph nodes (Fig. 2).

\section{Survival analysis}

Analyzing 350 out of 381 (92\%) patients with available follow-up data, we observed progressive disease in 141 $(40 \%)$ patients after a mean (median) follow-up of 56

Table 2 Binary logistic regression analysis of factors predicting retrieval of $\geq 12$ lymph nodes in CRC

\begin{tabular}{lllll}
\hline Variable & Level & HR & CI & $p$ value \\
\hline Tumor size & $>4.5$ & 2.12 & $1.26-3.56$ & 0.005 \\
T-classification & $>2$ & 2.87 & $1.70-4.85$ & $<0.001$ \\
N-classification & Positive & 1.89 & $1.14-3.13$ & 0.014 \\
Location & Right & 2.04 & $1.18-3.57$ & 0.012 \\
\hline
\end{tabular}

$H R$ hazard ratio, $C I$ confidence interval
(45) months (range 1-182). Mean time to progression was 15 months (median 7, range 0-88). At the end of follow-up, $118(34 \%)$ patients had died from cancer [16].

Disease progression occurred in 42.5, 36.1, 40, and $47.5 \%$ of patients with $1-9,10-19,20-29$, and $>29$ sampled lymph nodes $(p=0.684)$, respectively. In addition, $34.3,32.2,33.0$, and $37.5 \%$ of patients with $1-9,10-19$, $20-29$, or $>29$ retrieved lymph nodes died of disease $(p=0.885)$.

When we analyzed our cohort using the cut-off of 12 lymph nodes recommended by the AJCC/UICC TNM staging system, we observed disease progression in $41.2 \%$ of patients with $\leq 12$ compared with $39 \%$ of patients with $>12$ retrieved lymph nodes $(p=0.563)$. In addition, $32.8 \%$ of patients with $\leq 12$ and $33.8 \%$ of patients with $>12$ retrieved lymph nodes died of disease $(p=0.879)$.

When we restricted analysis to patients with $\mathrm{T} 3$ or T4 tumors irrespective of nodal status $(n=283)$, we observed disease progression in $57.8 \%$ of patients with $\leq 12$ compared with $46.6 \%$ of patients with $>12$ retrieved lymph nodes $(p=0.044$; 

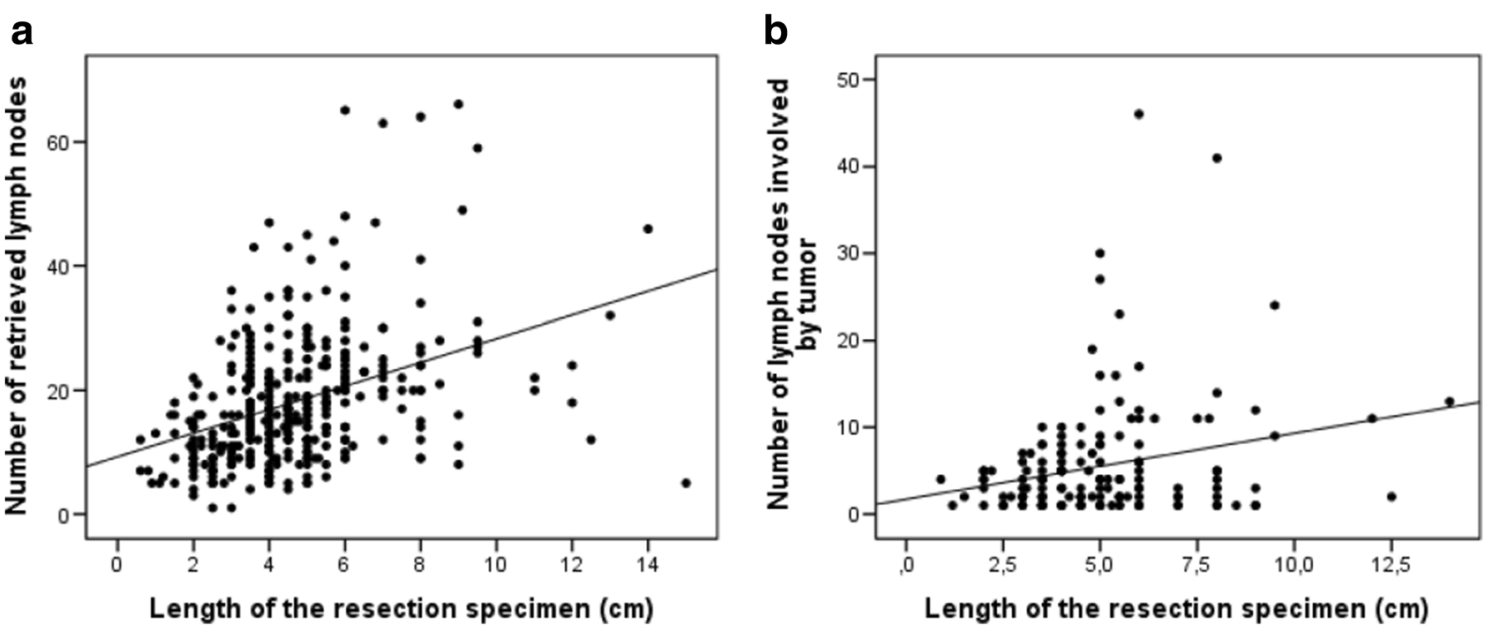

Fig. 2 Length of the resection specimen related to the number of retrieved lymph nodes (a). The number of lymph nodes involved by tumor (b)

Fig. 3a). Actuarial 5-year PFS rates were 42 and 52\%, respectively. In addition, $48.4 \%$ of patients with $\leq 12$ and $39.8 \%$ of patients with $>12$ retrieved lymph nodes died of disease ( $p=0.029$; Fig. 3b). Actuarial 5-year CSS rates were 52 and $61 \%$, respectively.
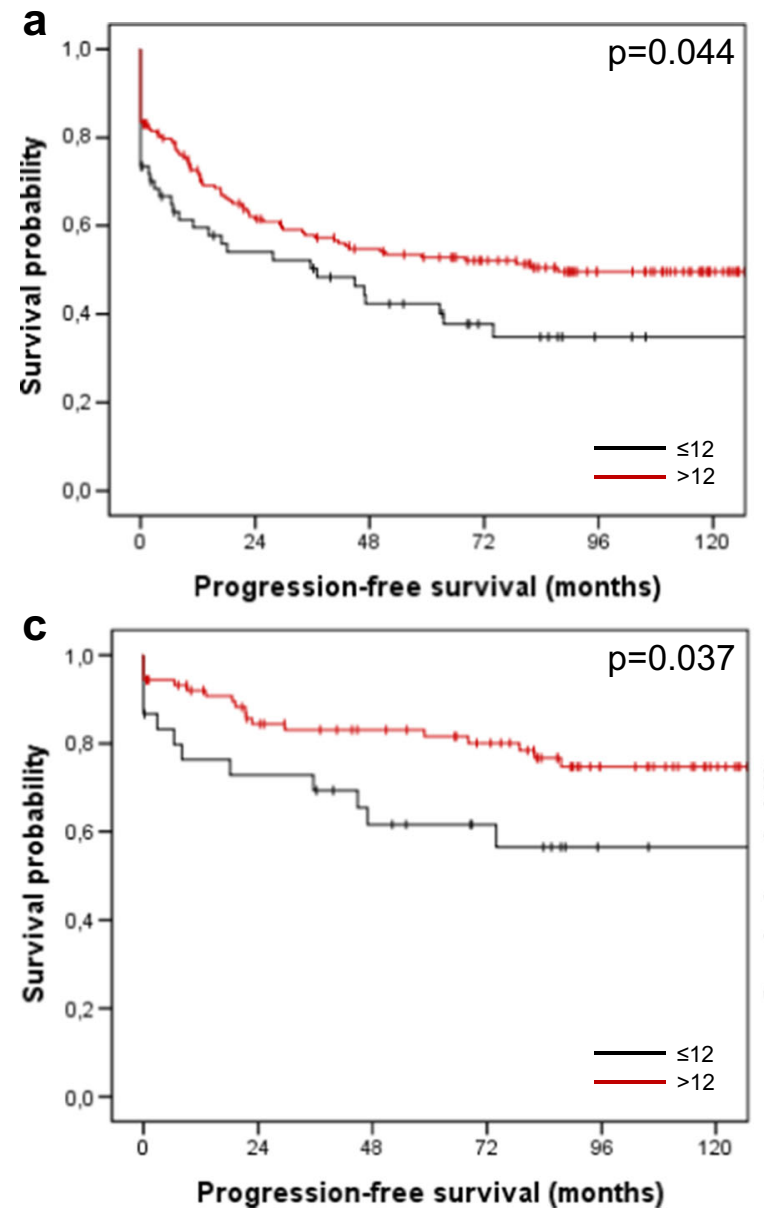

Fig. 3 Progression-free (a) and cancer-specific survival (b) of patients with T3/T4 cancer related to the number of retrieved lymph nodes $(\leq 12$ versus $>12$ nodes); progression-free (c) and cancer-specific survival (d) of
In patients with T3/T4, N0 disease ( $n=130)$, disease progression occurred in $40 \%$ of patients with $\leq 12$ compared with $21.6 \%$ of patients with $>12$ retrieved lymph nodes $(p=0.037$; Fig. 3c). Actuarial 5-year PFS rates were 60 and $81 \%$, respectively. In addition, $36.6 \%$ of patients with $\leq 12$ and $18.2 \%$ of

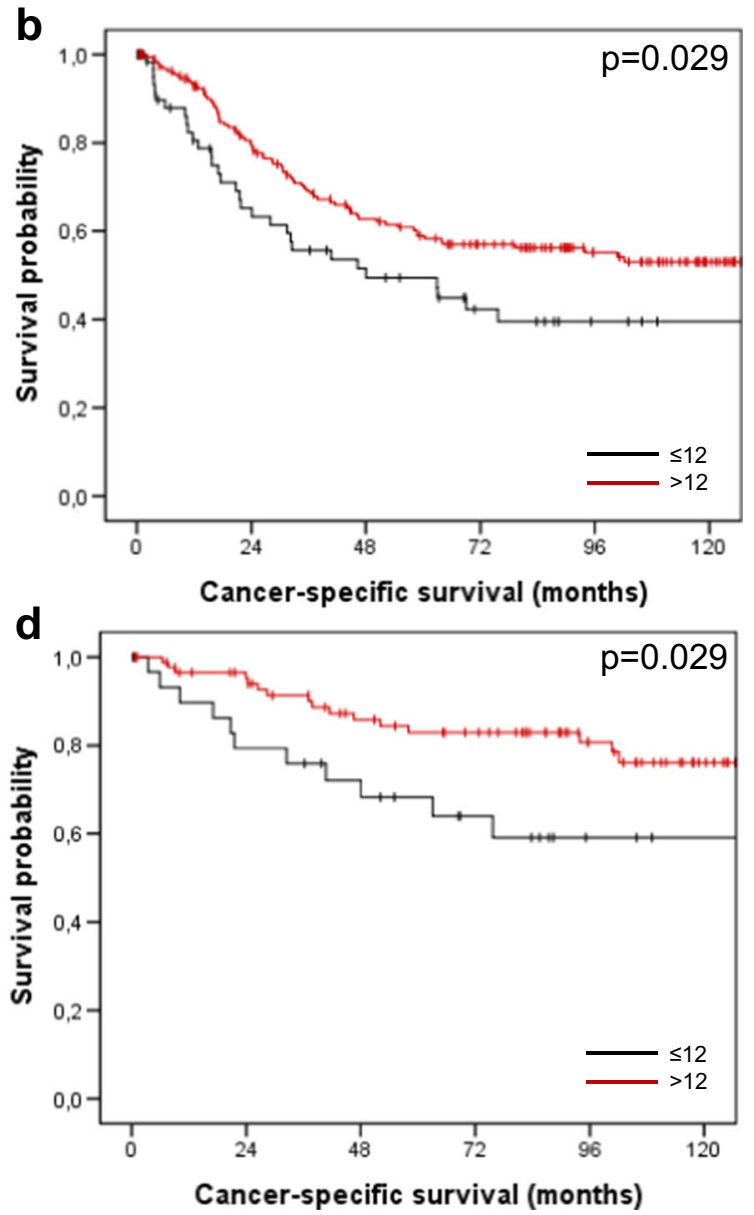

patients with T3/T4 N0 cancer related to the number of retrieved lymph nodes $(\leq 12$ versus $>12$ nodes $)$ 
Table 3 Multivariable analysis of prognostic factors for PFS and CSS in T3/T4 CRCs

\begin{tabular}{|c|c|c|c|c|c|c|c|}
\hline \multirow[b]{2}{*}{ Variable } & \multirow[b]{2}{*}{ Level } & \multicolumn{3}{|l|}{ PFS } & \multicolumn{3}{|l|}{ CSS } \\
\hline & & HR & CI & $p$ value & HR & CI & $p$ value \\
\hline Age & $>70$ & 1.15 & $0.80-1.63$ & 0.45 & 1.51 & $1.03-2.20$ & 0.036 \\
\hline Gender & Female & 1.13 & $0.79-1.62$ & 0.51 & 1.18 & $0.80-1.74$ & 0.41 \\
\hline Grade & $>2$ & 1.24 & $0.86-1.77$ & 0.25 & 1.75 & $1.19-2.58$ & 0.004 \\
\hline N-retrieval & $>12$ & 0.63 & $0.43-0.95$ & 0.025 & 0.54 & $0.35-0.82$ & 0.004 \\
\hline N-classification & $>0$ & 4.32 & $4.31-2.84$ & $<0.001$ & 4.61 & $2.95-7.21$ & $<0.001$ \\
\hline
\end{tabular}

PFS progression-free survival, $C S S$ cancer-specific-survival, $H R$ hazard ratio, $C I$ confidence interval, $N$-retrieval lymph node retrieval patients with $>12$ retrieved lymph nodes died of disease $(p=0.029$; Fig. 3d). Actuarial 5-year CSS rates were 67 and $84 \%$, respectively.

In Cox proportional hazards regression analysis, lymph node retrieval prove to be an independent prognostic factor for PFS and CSS of patients with T3/T4 tumors irrespective of nodal involvement (Table 3). When we performed Cox analysis in T3/T4 N0 patients, again lymph node retrieval proved to be an independent prognostic variable for PFS $(\mathrm{HR}=0.48$, $95 \% \mathrm{CI}=0.23-0.99, p=0.046)$ and $\mathrm{OS}(\mathrm{HR}=0.41,95 \%$ $\mathrm{CI}=0.19-0.90, p=0.026$ ), while age $>70$ years, female gender and grading did not show independent prognostic impact for both PFS ( $p=0.84, p=0.82$, and $p=0.75$, respectively) or OS ( $p=0.47, p=0.95$, and $p=0.51$, respectively).

\section{Discussion}

The prognosis of patients with $\mathrm{CRC}$ after tumor resection depends substantially on the presence of lymph nodes involved by tumor cells. The number of sampled (that is the number of histologically analyzed) lymph nodes has therefore been discussed as marker for adequate staging, quality of surgical therapy and pathological work-up, but also as independent prognostic marker guiding therapeutic decisions $[6,7]$.

According to our data, retrieval of more than 12 lymph nodes proved to be a significant prognostic factor in locally advanced (T3/T4) CRC in both univariable and multivariable analyses. Moreover, high T-classification and tumor stage, tumor size and location, as well as length of the resection specimen were all significantly associated with lymph node count. In concordance with our data, a systematic review [8] and further recent studies [9, 21-24] demonstrated significant prognostic impact of lymph node count in stage II disease. A reason for this may be the better selection of patients who are truly node negative and are thus cured by surgery alone [7]. However, this view has been challenged by publications arguing that a higher number of retrieved lymph nodes did not increase the proportion of stage III disease $[25,26]$. Also, in stage III cases and in mixed populations, several studies showed significant prognostic impact
[8-11, 27, 28]. A more thorough clearance of tumor cells by improved lymphadenectomy may explain the observed prognostic influence [7]. Accordingly, studies including ours, have demonstrated an association of lymph node retrieval with the length of the examined operation specimen [13, 24, 29-31].

However, independent of surgical extent und thoroughness of the pathological work-up, tumor- and/or patient-specific factors are influencing lymph node retrieval in colorectal cancer. According to our data, a higher number of lymph nodes was harvested in patients with lymph node involvement by tumor. This association has been reported previously [11, 21, 23]; however, not all studies showed this association [10]. Furthermore, T-classification and higher tumor stage were significantly associated with higher lymph node count. Both associations are in the line with literature data showing associations of lymph node retrieval with T-classification [13, 21, 23, 32] and AJCC/UICC stage [11, 13, 14, 21, 32-35]. Also, tumor size is, according to previous studies, an established predictor of lymph node yield [11, 13, 23, 29, 31, 36] that could be confirmed by our study. Other previously described factors were not found to be related to lymph node yield in our study. For instance, younger patient age has repeatedly been reported to be significantly associated with lymph node count $[9,11,13,14$, 23, 29, 31-33, 35, 37], but not in our cohort.

Another interesting determining factor for lymph node yield is tumor location. Apart from our analysis, several other studies have demonstrated higher numbers of lymph nodes retrieved from patients with right-sided, compared with left-sided cancers [9, 13, 29, 32, 34-38]. Differences in embryonic development or a greater length of the mesenteric root have been discussed as possible cause [7]. However, also a higher inflammatory response to right-sided tumors, which are often microsatellite instable, has been proposed and found in previous analyses [36, 39]. We were not able to prove this association, but the number of mismatch-repair deficient tumors was rather low in our cohort.

Since patient- and tumor-related factors play a major role for lymph node retrieval, the value of efforts, which aim to increase the lymph node yield, has been challenged [40]. Also, since several studies failed to prove prognostic impact [13-15, $34,36,40]$. These negative results may be due to different 
methodologies and heterogeneous study populations including different stages, both colon and rectum cancers, different cut-off values, but also small sample sizes. Of note, median numbers of retrieved lymph nodes vary greatly among published reports, according to a review by McDonald et al. [6] ranging from 6 to 21 .

It has to be mentioned as limitation that our study cohort is heterogeneous with respect to inclusion of both, colon and rectum cancers. We excluded patients with rectal cancer that had undergone neoadjuvant chemotherapy or radiotherapy before surgery to keep our study cohort more homogenous. Of note, previous studies have revealed lower numbers of retrieved lymph nodes after neoadjuvant treatment [21, 23, 33, 41]. Another limitation of our study is the retrospective character of our analysis. Previous studies have shown that factors related to surgical procedure were related to lymph node harvest, including open versus laparoscopic approach. Those factors could not be analyzed here in detail as data were not available in this regard. Of note, with complete mesocolic excision (CME), a standardized surgical procedure is now available that leads to better surgical specimens and allows improved quality control. Therefore, future studies dealing with lymph node yield in colon cancer surgery should be done with pathologically graded CME specimens to increase comparability [42].

In conclusion, higher AJCC/UICC stage, tumor size, and right-sided location, as well as the length of the operation specimen were factors associated with lymph node retrieval. Rational cut-off values defining the minimum number of lymph nodes to be assessed for staging of CRC may thus be adjusted by these variables. According to our data, analysis of more than 12 lymph nodes is significantly associated with improved outcome in patients with locally advanced (T3/T4) disease.

Acknowledgements Open access funding provided by Medical University of Graz.

\section{Compliance with ethical standards}

Conflict of interest The authors declare that they have no conflict of interest.

Open Access This article is distributed under the terms of the Creative Commons Attribution 4.0 International License (http:// creativecommons.org/licenses/by/4.0/), which permits unrestricted use, distribution, and reproduction in any medium, provided you give appropriate credit to the original author(s) and the source, provide a link to the Creative Commons license, and indicate if changes were made.

\section{References}

1. Torre LA, Bray F, Siegel RL et al (2015) Global cancer statistics, 2012. CA: A Cancer J Clin 65:87-108

2. Resch A, Langner C (2013) Lymph node staging in colorectal cancer: old controversies and recent advances. World J Gastroenterol $19: 8515-8526$
3. Compton CC (2007) Optimal pathologic staging: defining stage II disease. Clin Cancer Res 13:6862s-6870s

4. International Union Against Cancer (2009) TNM classification of malignant tumours, 7th edn. Wiley-Blackwell, West-Sussex

5. Rousseau B, Chibaudel B, Bachet J-B et al (2010) Stage II and stage III colon cancer: treatment advances and future directions. Cancer J 16:202-209

6. McDonald JR, Renehan AG, O'Dwyer ST, Haboubi NY (2012) Lymph node harvest in colon and rectal cancer: current considerations. World J Gastrointest Surg 4:9-19

7. Destri GL, Di Carlo I, Scilletta R et al (2014) Colorectal cancer and lymph nodes: the obsession with the number 12 . World $\mathrm{J}$ Gastroenterol 20:1951-1960. doi:10.3748/wjg.v20.i8.1951

8. Chang GJ, Rodriguez-Bigas MA, Skibber JM, Moyer VA (2007) Lymph node evaluation and survival after curative resection of colon cancer: systematic review. J Natl Cancer Inst 99:433-441

9. Vather R, Sammour T, Kahokehr A et al (2008) Lymph node evaluation and long-term survival in stage II and stage III colon cancer: a national study. Ann Surg Oncol 16:585-593

10. Budde CN, Tsikitis VL, Deveney KE et al (2014) Increasing the number of lymph nodes examined after colectomy does not improve colon cancer staging. J Am Coll Surg 218:1004-1011

11. Onitilo AA, Stankowski RV, Engel JM, Doi SAR (2013) Adequate lymph node recovery improves survival in colorectal cancer patients. J Surg Oncol 107:828-834

12. Benson AB (2004) American Society of Clinical Oncology recommendations on adjuvant chemotherapy for stage II Colon cancer. J Clin Oncol 22:3408-3419

13. Moro-Valdezate D, Pla-Martí V, Martín-Arévalo J et al (2013) Factors related to lymph node harvest: does a recovery of more than $12 \mathrm{im}$ prove the outcome of colorectal cancer? Color Dis 15:1257-1266

14. McFadden C, McKinley B, Greenwell B et al (2013) Differential lymph node retrieval in rectal cancer: associated factors and effect on survival. J Gastrointest Oncol 4:158-163

15. Tsikitis VL, Larson DL, Wolff BG et al (2009) Survival in stage III colon cancer is independent of the total number of lymph nodes retrieved. J Am Coll Surg 208:42-47

16. Betge J, Pollheimer MJ, Lindtner RA et al (2012) Intramural and extramural vascular invasion in colorectal cancer: prognostic significance and quality of pathology reporting. Cancer 118:628-638

17. Moertel CG, Fleming TR, Macdonald JS et al (1990) Levamisole and fluorouracil for adjuvant therapy of resected colon carcinoma. N Engl J Med 322:352-358

18. Bosman FT, Carneiro F, Hruban RH, Theise ND (2010) WHO classification of tumours of the digestive system, 4th edn. IARC, Lyon

19. Harbaum L, Pollheimer MJ, Kornprat P et al (2011) Keratin 7 expression in colorectal cancer-freak of nature or significant finding? Histopathol 59:225-234

20. Lugli A, Tzankov A, Zlobec I, Terracciano LM (2008) Differential diagnostic and functional role of the multi-marker phenotype CDX2/CK20/CK7 in colorectal cancer stratified by mismatch repair status. Mod Pathol 21:1403-1412

21. Evans MD, Barton K, Rees A et al (2008) The impact of surgeon and pathologist on lymph node retrieval in colorectal cancer and its impact on survival for patients with Dukes' stage B disease. Color Dis 10:157-164

22. Tsai H-L, Cheng K-I, Lu C-Y et al (2008) Prognostic significance of depth of invasion, vascular invasion and numbers of lymph node retrievals in combination for patients with stage II colorectal cancer undergoing radical resection. J Surg Oncol 97:383-387

23. Mekenkamp LJM, van Krieken JHJM, Marijnen CAM et al (2009) Lymph node retrieval in rectal cancer is dependent on many factors - the role of the tumor, the patient, the surgeon, the radiotherapist, and the pathologist. Am J Surg Pathol 33:1547-1553

24. Norwood MGA, Sutton AJ, West K et al (2010) Lymph node retrieval in colorectal cancer resection specimens: national standards 
are achievable, and low numbers are associated with reduced survival. Color Dis 12:304-309

25. Kukreja SS, Esteban-Agusti E, Velasco JM, Hieken TJ (2009) Increased lymph node evaluation with colorectal cancer resection: does it improve detection of stage III disease? Arch Surg 144:612-617

26. Moore J, Hyman N, Callas P, Littenberg B (2010) Staging error does not explain the relationship between the number of lymph nodes in a colon cancer specimen and survival. Surgery 147:358-365

27. Le Voyer TE (2003) Colon cancer survival is associated with increasing number of lymph nodes analyzed: a secondary survey of intergroup trial INT-0089. J Clin Oncol 21:2912-2919

28. Kritsanasakul A, Boonpipattanapong T, Wanitsuwan W et al (2011) Impact of lymph node retrieval on surgical outcomes in colorectal cancers. J Surg Oncol 106:238-242

29. Fan L, Levy M, Aguilar CE et al (2011) Lymph node retrieval from colorectal resection specimens for adenocarcinoma: is it worth the extra effort to find at least 12 nodes? Color Dis 13:1377-1383

30. Gravante G, Parker R, Elshaer M et al (2016) Int J Surg 25:153157. doi:10.1016/j.ijsu.2015.12.062

31. Wright FC, Law CHL, Last L et al (2003) Lymph node retrieval and assessment in stage II colorectal cancer: a population-based study. Ann Surg Oncol 10:903-909

32. Gonsalves WI, Kanuri S, Tashi T et al (2011) Clinicopathologic factors associated with lymph node retrieval in resectable colon cancer: a veterans' affairs central cancer registry (VACCR) database analysis. J Surg Oncol 104:667-671

33. Tekkis PP, Smith JJ, Heriot AG et al (2006) A national study on lymph node retrieval in resectional surgery for colorectal cancer. Dis Colon rectum 49:1673-1683
34. Kuo Y-H, Lee K-F, Chin C-C et al (2012) Does body mass index impact the number of LNs harvested and influence long-term survival rate in patients with stage III colon cancer? Int J Color Dis 27: 1625-1635

35. Chou JF, Row D, Gonen M et al (2010) Clinical and pathologic factors that predict lymph node yield from surgical specimens in colorectal cancer: a population-based study. Cancer 116:2560 2570

36. Kim YW, Jan KM, Jung DH et al (2013) Histological inflammatory cell infiltration is associated with the number of lymph nodes retrieved in colorectal cancer. Anticancer Res 33:5143-5150

37. Sarli L, Bader G, Iusco D et al (2005) Number of lymph nodes examined and prognosis of TNM stage II colorectal cancer. Eur J Cancer 41:272-279

38. Bilimoria KY, Palis B, Stewart AK et al (2008) Impact of tumor location on nodal evaluation for colon cancer. Dis Colon rectum 51: 154-161

39. Eveno C, Nemeth J, Soliman $\mathrm{H}$ et al (2010) Association between a high number of isolated lymph nodes in T1 to T4 N0M0 colorectal cancer and the microsatellite instability phenotype. Arch Surg 145:12-17

40. Wong SL, Ji H, Hollenbeck BK et al (2007) Hospital lymph node examination rates and survival after resection for colon cancer. JAMA 298:2149-2154

41. Govindarajan A, Gonen M, Weiser MR et al (2011) Challenging the feasibility and clinical significance of current guidelines on lymph node examination in rectal cancer in the era of neoadjuvant therapy. J Clin Oncol 29:4568-4573

42. West NP, Kennedy RH, Margo T et al (2014) Morphometric analysis and lymph node yield in laparoscopic complete mesocolic excision performed by supervised trainees. Br J Surg 101:1460-1467 